Research Article

\title{
Sustainable Supplier Evaluation and Selection of Fresh Agricultural Products Based on IFAHP-TODIM Model
}

\author{
Yupei Du, ${ }^{1}$ Di Zhang $\left(\mathbb{D},{ }^{2}\right.$ and Yue Zou $\mathbb{D}^{3}$ \\ ${ }^{1}$ School of Aeronautics and Astronautics, Sichuan University, Chengdu 610065, China \\ ${ }^{2}$ Cyberspace Administration of Sichuan, Chengdu 610065, China \\ ${ }^{3}$ Business School, Sichuan University, Chengdu 610065, China \\ Correspondence should be addressed to Yue Zou; 2019225025109@stu.scu.edu.cn
}

Received 26 June 2020; Accepted 21 November 2020; Published 4 December 2020

Academic Editor: Luigi Rodino

Copyright (C) 2020 Yupei Du et al. This is an open access article distributed under the Creative Commons Attribution License, which permits unrestricted use, distribution, and reproduction in any medium, provided the original work is properly cited.

In recent years, increasing pollution of the ecological environment, excessive use of pesticides, and lack of effective management of agricultural product supply chains have made the problem of having a green and safe supply of fresh food increasingly prominent. The sustainability of the fresh agricultural products supply has become an inevitable focus in the development of agricultural enterprises. There are some problems in the supply chain of fresh agricultural products, such as scattered production sites and difficult logistics transportation, which makes it difficult for enterprises to choose reliable suppliers. Supplier selection is a key component of sustainable supply chain management, and the criteria for evaluating the quality of sustainable suppliers are often affected by economic, social, and environmental factors. Therefore, from the perspective of sustainability, based on triple bottom line theory and comprehensively considering the three aspects of society, environment, and economy, this paper proposes a novel evaluation index system for the selection of sustainable suppliers of fresh agricultural products. This paper innovatively integrates the intuition fuzzy analytic hierarchy process and TODIM (an acronym in Portuguese of interactive and multiple attribute decision-making), and these are applied to select sustainable suppliers. Finally, the integration method is applied to the example, and a sensitivity analysis is carried out to verify the validity of the evaluation model.

\section{Introduction}

Selection of fresh agricultural product suppliers is one of the most critical links in the agricultural product supply chain. Green and sustainable agricultural product supply is not only related to the development of food enterprises, but it also has a greater impact on people's livelihood. In recent years, with the problems of ecological environment pollution, excessive use of pesticides and fertilizers, and excessive use of additives in food processing in farmland, ensuring the sustainability of agricultural products has become increasingly problematic. For example, "Sudan red," "poisonous cowpea," and other vicious events have aroused widespread public concern about the safety of agricultural product supply. Taking China as an example, due to the lagging development of logistics transportation in the agricultural product supply chain, agricultural product production is relatively fragmented, and intersubject information cannot be circulated quickly and effectively. This makes it difficult to choose safe and sustainable suppliers in the agricultural product supply chain. Therefore, sustainable supplier selection of fresh agricultural products has become a key link in the management of green agricultural product supply chains. Selection of fresh agricultural product suppliers must not only consider the cost and technology but also environmental pollution, resource consumption, and social responsibility. In summary, how to effectively assess the sustainability of fresh agricultural product suppliers is an important issue for companies to implement sustainable supply chain management.

\section{Literature Review}

At present, domestic and foreign studies on the food supply chain and supplier selection methods are relatively numerous, while there are relatively few studies on the selection 
of sustainable suppliers of fresh agricultural products. A characteristic of the food supply chain is that food is perishable [1], and the freshness of food will directly affect the quality and safety [2]. Fresh food is a critical part in the food supply chain, which greatly affects the safety of consumers' diets. However, in this supply chain, there are a large number of intermediaries between farmers and retailers [3]. Under the trend of continuous development of food safety and quality standards, supermarkets and other suppliers have to pay a huge cost to purchase from many small-scale agricultural producers [4]. Therefore, the selection of sustainable suppliers in the fresh food supply chain has become a key issue that needs to be studied.

Supplier selection is a key component of sustainable supply chain management [5]. The focus of sustainable supply chain development is the type of supply chain and the social and environmental responsibilities of products [6], while the sustainability of agricultural food supply chains obviously involves significant environmental and social impacts [7]. The sustainability of food includes environmental issues, social issues, and expected returns [8]. Therefore, previous research has attempted to establish a sustainable agricultural food supply chain evaluation index system from the three dimensions of social responsibility, economic benefits, and environmental protection. As the material basis for agricultural product production, the ecological environment has always been the main consideration in constructing a sustainable evaluation index system. Gerbens-Leenes et al. [9] applied environmental indicators to their evaluation of the environmental sustainability of food production. Solér et al. [10] explored the use of environmental information at different stages in the food supply chain. Cellura et al. [11] evaluated the sustainability of crop production and consumption from the perspectives of energy consumption and environmental burden.

Corporate social responsibility is considered to be one of the major factors impacting the food supply chain [12]. Spence et al. [13] discussed the evolution from corporate social responsibility to food supply chain responsibility. Chkanikova and Mont [14] systematically elaborated the reasons and obstacles for food retailers to fulfill their supply chain responsibilities. Krejci et al. [15] studied the influence of social factors on the long-term sustainability of food supply centers. Chen et al. [16] determined optimal suppliers in the sustainable food supply chain from the perspective of social responsibility. Stranieri et al. [17] discussed the effect of implementing corporate social responsibility activities on the vertical restructuring of the food supply chain.

Economic benefit is the basic indicator of sustainable supply assessment. It is generally combined with environmental performance or social performance to evaluate the sustainability of the supply chain [18-20]. In addition, some researchers have combed the existing literature on agricultural fresh food supply chain quality (AFSCQ). They found that sustainable management is one of the key issues in AFSCQ research, and performance evaluations of the agricultural fresh food supply chain are still in the development stage [21]. However, most of the previous research has focused on sustainability assessment of the food supply chain and agricultural product supply chain. Sustainability assessments of fresh agricultural product suppliers are basically nonexistent and lack a systematic measurement framework.

Selection of sustainable suppliers requires evaluation of supplier performance based on multiple criteria [22], which includes two stages: determination of indicator weights and supplier ranking. The two-stage evaluation part involves two types of uncertainty: individual uncertainty and group uncertainty [23]. Individual uncertainty refers to the ambiguity of an individual's thinking and expression [24], and group uncertainty refers to the ambiguity of different people's preferences for something [23]. Since the decision process involves uncertain information, various methods based on fuzzy set theory are often used in the field of supplier selection to capture fuzzy or ambiguous information [25]. Among the commonly used multiattribute decision-making methods for determining weights, there are, for example, AHP [26], ANP [27], and DEMATEL [28]. These traditional weighting methods cannot deal well with the uncertainty and inaccuracy of decision information. In the supplier ranking method, compared with DEA [29], PROMETHEE [30], and TOPSIS [31] methods, the TODIM multiattribute decision-making method considers the psychological behavior of decision-makers [32] and can deal with uncertainties The problem is in the environment [33], but the TODIM method directly measures the distance between the fuzzy numbers and decomposes the fuzzy information into clear values at the beginning, which may lead to the loss of important information in decisionmaking problems [34]. Considering the ambiguity of decision information, applying the IF intuitionistic fuzzy set theory to the AHP method (i.e., IFAHP) can better deal with the hesitation in decision-making [35]. Thus, this article chose the IFAHP-TODIM integration method and applied it to the selection of sustainable suppliers of fresh agricultural products. Existing research on the selection of sustainable suppliers of fresh agricultural products has not yet used this integrated method, so we also expand on new ideas for subsequent scholars to study.

\section{The Evaluation Index System of Fresh Agricultural Product Sustainable Suppliers Based on Triple Bottom Line}

Sustainable supply chain management has become the focus of supply chain field. One of the most basic means of sustainable supply chain management is supplier selection [36]. Sustainable supplier selection is a key factor in sustainable supply chain management [37], because the supplier is at the beginning of the supply chain, and its economic, environmental, and social performance will have a significant impact on the downstream enterprises of the supply chain [25]. Traditional supplier selection only focuses on economic factors, but in the changing market, sustainable supply chain management should be adopted, that is, 
environmental and social standards [38, 39] should be considered. Choosing the right supplier based on sustainability criteria (economy, environment, and society) can help enterprises achieve sustainable development [40]. Sustainable supply chain management in the field of fresh agricultural products is facing economic, social, and ecological challenges. This sustainability is influenced by many factors, including economic, social, and environmental aspects, namely, the triple bottom line (TBL) principle (Figure 1). In the organization of production activities, enterprises not only focus on economic development but also consider their own social responsibilities and possible environmental pollution. If you simply pursue profitability and ignore social and environmental responsibilities, companies may move to oppose consumers and society and will face the dilemma of rootless trees. Unification of economic development, social responsibility, and environmental responsibility is the foundation for sustainable development of an enterprise and its longevity.

\section{1. "Economic Bottom Line" Evaluation Index. Economic} development is the lifeblood of an enterprise, and economic benefits (gross output value/production cost) are an important part of measuring enterprise performance. This article selects three indicators of energy consumption, logistics cost, and net product price from the cost dimension to construct an economic bottom line indicator system.

3.2. "Social Bottom Line" Evaluation Index. The social bottom line measures the ability of business organizations to fulfill their social responsibilities. Social responsibility includes protection of consumer rights, social welfare, green safety, and other components. This article selects six specific indicators from the dimensions of food safety and packaging materials - to reduce food additives, green R \& D and innovation, reusability, biodegradable products, use of recycled materials, and use of hazardous substances-to build a social bottom line indicator system.

\section{3. "Environmental Bottom Line" Evaluation Index.} Sustainable development focuses on the coordinated development of social, economic, and environmental aspects. Changes in the vectors of indicators in these areas are expected to increase incrementally. Among them, ecological environmental protection is the prerequisite for sustainable economic development. Based on the theory of sustainable development, this article refers to the indicators recommended by the "Guide to Sustainability Reporting." The article selects seven indicators-ISO14000 certification, environmental policies and plans, environmental remediation, environmental governance, air pollutant production, wastewater production, and solid waste production-from three dimensions-environmental management system, environmental protection, and pollution generation-and builds an environmental baseline indicator system. The established evaluation index system for the suppliers of fresh agricultural products is shown in Table 1.

\section{Methodology}

The intuitionistic fuzzy analytic hierarchy process decomposes complex decision-making problems into an orderly hierarchical structure in the order of general goals, subgoals at various levels, and evaluation criteria, and then relevant experts score the indicators in the structural model. With the help of expert scores and an intuitionistic fuzzy number correspondence table (Table 2), an intuitionistic fuzzy judgment matrix is established. Then, after a consistency test, the index weights at all levels are finally obtained to assist decision-making. This method can accurately reflect the uncertainty of the decision-making subject to the evaluated object to a certain extent, and it can unify the quantitative and qualitative indicators. In addition, when the judgment matrix is not consistent, an intuitionistic fuzzy judgment matrix that meets the requirements can be obtained by adjusting the parameters, and distortion of the original data is avoided as much as possible. The TODIM multiattribute decision-making method has been widely used in multiattribute decision-making problems such as intuitionistic fuzzy numbers, hesitant fuzzy numbers, and hesitant fuzzy language because it can fully consider the psychological behavior of decision-makers and obtain decision results that meet the preferences of decision-makers. In this study, the intuitionistic fuzzy analytic hierarchy process combined with the TODIM multiattribute decisionmaking method was used to select suppliers of fresh agricultural products. This process is specified in Figure 2.

\subsection{Construction of the Intuitionistic Fuzzy Judgment Matrix.} The first step was to collect the opinions of relevant experts on the importance of each indicator. For the 6 first-level indicators and 16 second-level indicators in the indicator system, we established seven intuitive fuzzy judgment matrices according to the criteria corresponding to the scores in Table 2 and the fuzzy numbers. Then, we made a pairwise comparison of the indicators of each layer to construct a $R=\left(r_{i j}\right)_{n \times n}$ square matrix, where $i$ and $j$ represent the rows and columns in the judgment matrix, respectively. $r_{i j}=\left(u_{i j}, v_{i j}\right)(i, j=1,2, \ldots, n)$, where $r_{i j}=\left(u_{i j}, v_{i j}\right)$, in which $u_{i j}$ indicates the degree that the $i$ th index is better than the $j$ th index; $v_{i j}$ indicates the $i$ th index is inferior to the $j$ th index; $\pi_{i j}$ represents the degree of hesitation, $\pi_{i j}=1-u_{i j}-v_{i j}$.

The basis for constructing the intuitionistic fuzzy judgment matrix is to grade the opinions of experts in the field of fresh agricultural product suppliers. For the comparison between qualitative indicators, see Table 2. The scale corresponds to expert score and intuitionistic fuzzy number. The last digit of the intuitionistic fuzzy number represents uncertainty (i.e., ambiguity). An intuitionistic fuzzy judgment matrix was constructed according to the corresponding fuzzy numbers obtained in Table 2 , so as to visually 


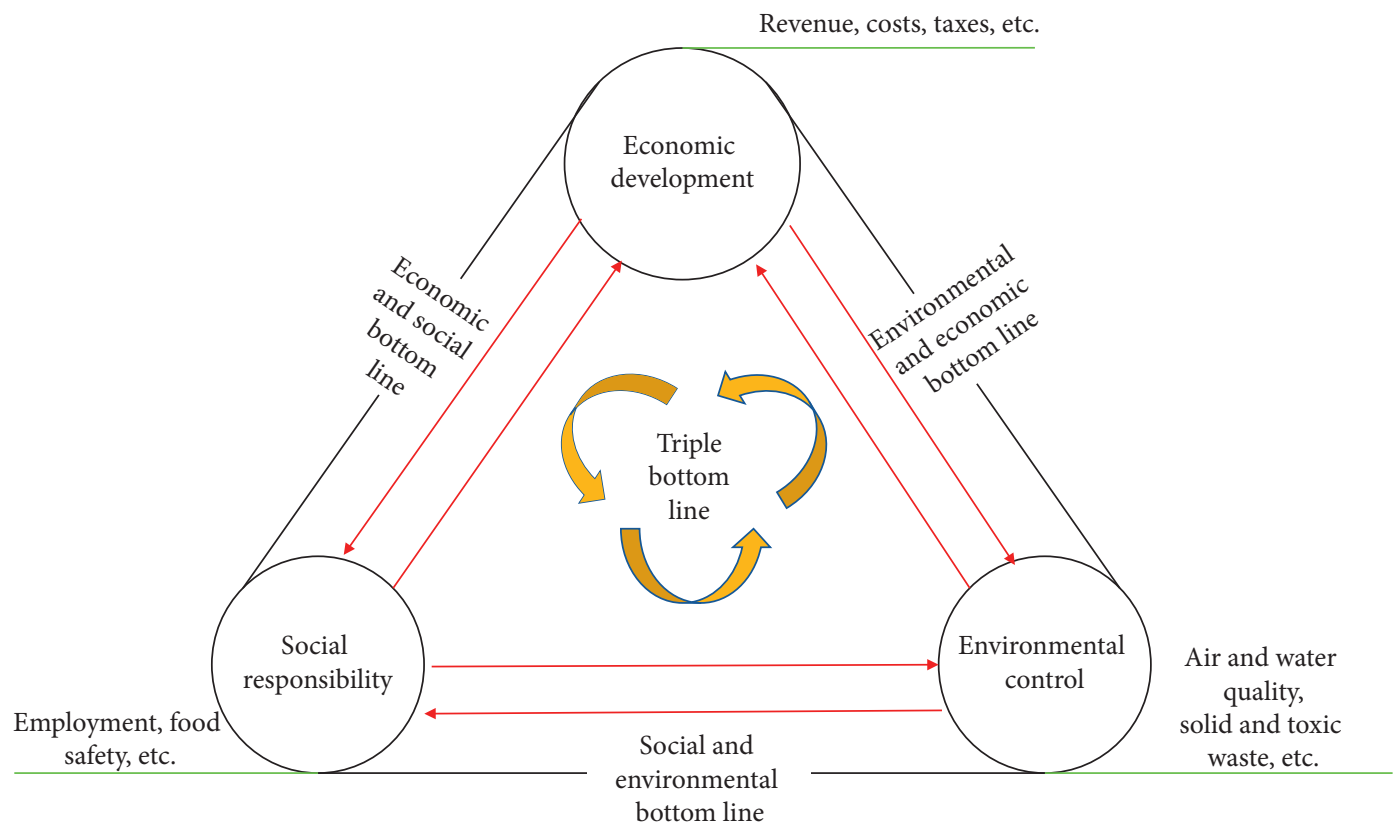

Figure 1: Triple bottom line.

TABLE 1: Evaluation index system of fresh agricultural product sustainable suppliers based on triple bottom line.

\begin{tabular}{|c|c|c|c|}
\hline Target layer & Standard layer & Indicator layer & Explanation layer \\
\hline $\begin{array}{l}\text { Environmental } \\
\text { control }\end{array}$ & $\begin{array}{l}\text { Environmental management } \\
\text { system } A_{1}\end{array}$ & $\begin{array}{c}\text { ISO } 14000 \text { certification } B_{11} \\
\text { Environmental policy and } \\
\text { plan } B_{12} \\
\text { Environmental restoration } \\
B_{21} \\
\text { Environmental governance } \\
B_{22} \\
\end{array}$ & $\begin{array}{l}\text { Environmental certification held by the supplier } \\
\text { Supplier environmental protection policy planning, } \\
\text { implementation, and review } \\
\text { Supplier efforts to eliminate contamination in the } \\
\text { media } \\
\text { Suppliers efforts to harmlessly dispose of waste }\end{array}$ \\
\hline & Cost $A_{3}$ & $\begin{array}{l}\text { Energy consumption } B_{31} \\
\text { Logistics costs } B_{32} \\
\text { Product net price } B_{33}\end{array}$ & $\begin{array}{l}\text { Energy consumption per unit of agricultural product } \\
\text { Total cost of agricultural products } \\
\text { Average net price per unit of agricultural product }\end{array}$ \\
\hline $\begin{array}{l}\text { Economic } \\
\text { development }\end{array}$ & Pollution $A_{4}$ & $\begin{array}{l}\text { Air pollutant production } \\
\qquad B_{41} \\
\text { Wastewater production } \\
B_{42} \\
\text { Solid waste generation } B_{43}\end{array}$ & $\begin{array}{c}\text { Daily average volume of wastewater } \\
\text { Average daily solid waste volume }\end{array}$ \\
\hline Social responsibility & $\begin{array}{l}\text { Use of packaging materials } \\
\qquad A_{5}\end{array}$ & $\begin{array}{l}\text { Reusability } B_{51} \\
\text { Biodegradable products } \\
\qquad B_{52} \\
\text { Use recycled materials } B_{53} \\
\text { Use of hazardous } \\
\text { substances } B_{54} \\
\text { Reduce food additives } B_{61} \\
\text { Green R \& D and } \\
\text { innovation } B_{62}\end{array}$ & $\begin{array}{c}\text { Reusable product percentage } \\
\text { Percentage of biodegradable products } \\
\text { Percentage of products using recycled materials } \\
\text { Daily use of harmful substances } \\
\text { Ability to ensure green food safety } \\
\text { Ability to innovate new clean technologies, processes, } \\
\text { and practices }\end{array}$ \\
\hline
\end{tabular}

check the relative importance of the indicators, and then a data consistency test was constructed.

4.2. Inspection Consistency Calculation. The second step was to conduct a consistency test on the collected expert evaluation opinions. If the requirements are not met, it means that the experts' evaluations of the relative importance of the indicators are not uniform. Unlike traditional analytic hierarchy processes, intuitionistic fuzzy analytic hierarchy processes can iterate through formulas and set parameters to avoid rescoring experts. The consistency test 
TABLE 2: Scale table corresponding to fuzzy numbers and ratings.

\begin{tabular}{lr}
\hline Preference evaluation & Intuitionistic fuzzy number \\
\hline Extremely important & $(0.90,0.10,0.00)$ \\
Very important & $(0.80,0.15,0.05)$ \\
Important & $(0.70,0.20,0.10)$ \\
More important & $(0.60,0.25,0.15)$ \\
Equally important & $(0.50,0.30,0.20)$ \\
Less important & $(0.40,0.45,0.15)$ \\
Unimportant & $(0.30,0.60,0.10)$ \\
Very unimportant & $(0.20,0.75,0.05)$ \\
Extremely unimportant & $(0.10,0.90,0.00)$ \\
\hline
\end{tabular}

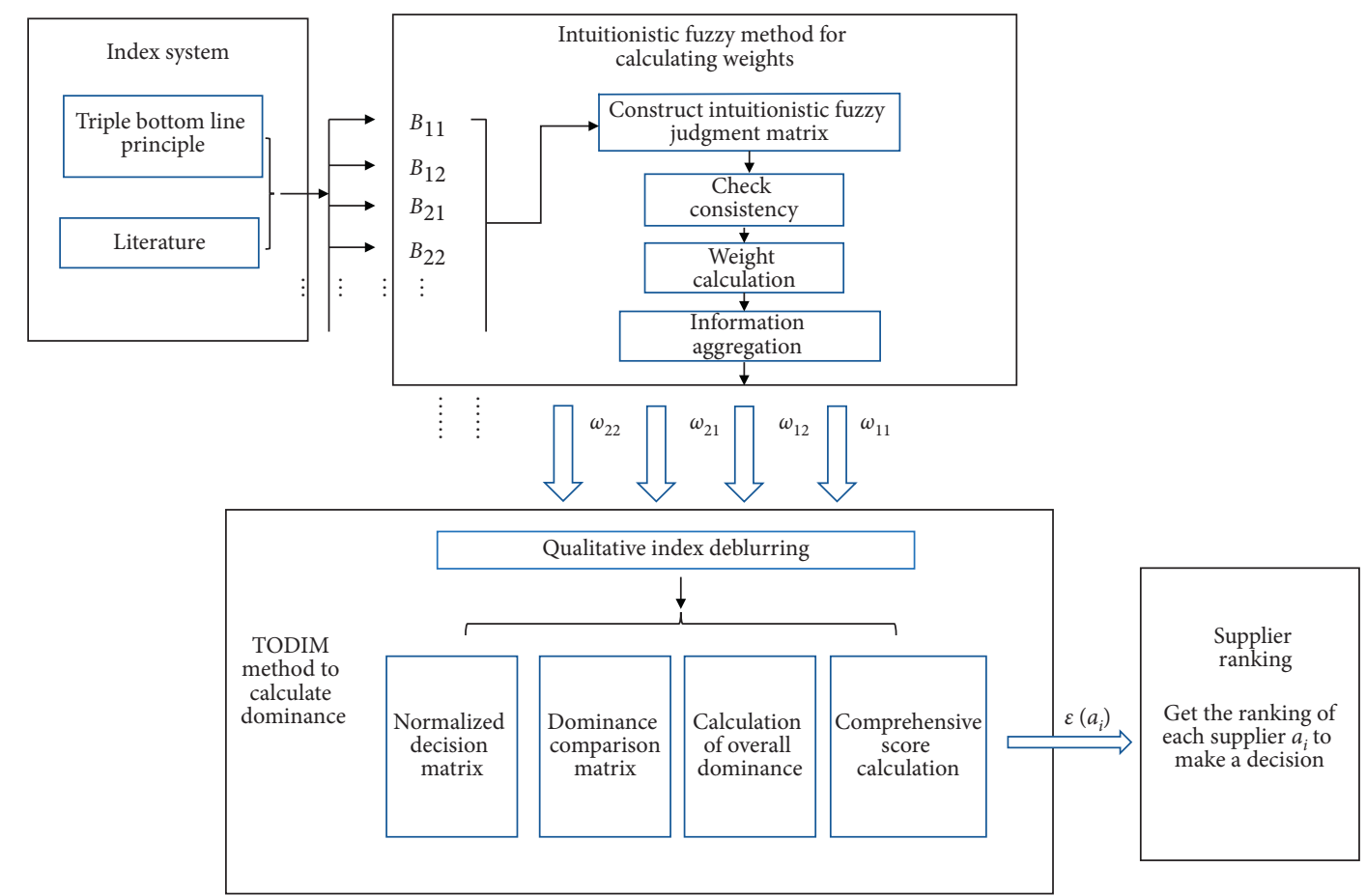

FIGURE 2: Supplier selection flowchart.

formula for distance measurements [41] based on intuitionistic fuzzy information is given as follows [42]:

$$
\begin{aligned}
\mathrm{d}(\bar{R}, R) & =\frac{1}{2(n-1)(n-2)} \sum_{i=1}^{n} \sum_{j=1}^{n}\left(\left|\overline{u_{i j}}-u_{i j}\right|\right. \\
& \left.+\left|\overline{v_{i j}}-v_{i j}\right|+\left|\overline{\pi_{i j}}-\pi_{i j}\right|\right),
\end{aligned}
$$

where $R$ is the intuitionistic fuzzy judgment matrix obtained by comparing pairs of indicators at all levels and $\bar{R}$ is the intuitionistic fuzzy consistency judgment matrix $\bar{R}=\left(\overline{r_{i j}}\right)_{n \times}$ $n$ obtained according to the following calculation formula [42]:

(1) When $j>i+1$, let $\bar{R}=\left(\bar{u}_{i j}, \bar{v}_{i j}\right)$, where

$$
\bar{u}_{i j}=\sqrt[j-i-1]{\frac{\prod_{t=i+1}^{j-1} u_{i t} u_{t j}}{\sqrt[j-i-1]{\prod_{t=i+1}^{j-1} u_{i t} u_{t j}+\sqrt[j-i-1]{\prod_{t=i+1}^{j-1}\left(1-u_{i t}\right)\left(1-u_{t j}\right)}}}}
$$

$$
\bar{v}_{i j}=\sqrt[j-i-1]{\frac{\prod_{t=i+1}^{j-1} v_{i t} v_{t j}}{\sqrt[j-i-1]{\prod_{t=i+1}^{j-1} v_{i t} v_{t j}+\sqrt[j-i-1]{\prod_{t=i+1}^{j-1}\left(1-v_{i t}\right)\left(1-v_{t j}\right)}}}}
$$

(2) When $j=i+1, \overline{r_{i j}}=r_{i j}$. 
(3) When $j<i+1, \overline{r_{i j}}=\left(\bar{v}_{i j}, \bar{u}_{i j}\right)$.

The intuitionistic fuzzy consistency judgment matrix $\bar{R}=$ $\left(\overline{r_{i j}}\right)_{n \times n}$ is calculated according to the above formula and substituted into equation (1) for a consistency check. If $\mathrm{d}(\bar{R}, t R)<0.1$, it passes the consistency test, and otherwise, it fails the consistency test. When the consistency test fails, the parameter $\sigma$ is introduced into the iteration, that is, the intuitionistic fuzzy consistency judgment matrix is transformed by adjusting the parameter $\sigma$ until the consistency test is passed. Let the parameter $\sigma \in[0,1]$, then the consistency check formula is as follows [42]:

$$
\begin{aligned}
\widetilde{u_{i j}} & =\frac{\left(u_{i j}\right)^{1-\sigma}\left(\overline{u_{i j}}\right)^{\sigma}}{\left(u_{i j}\right)^{1-\sigma}\left(\overline{u_{i j}}\right)^{\sigma}+\left(1-u_{i j}\right)^{1-\sigma}\left(1-\overline{u_{i j}}\right)^{\sigma}}, \quad i, j \\
& =1,2, \ldots, n, \\
\widetilde{v_{i j}} & =\frac{\left(v_{i j}\right)^{1-\sigma}\left(\overline{v_{i j}}\right)^{\sigma}}{\left(v_{i j}\right)^{1-\sigma}\left(\overline{v_{i j}}\right)^{\sigma}+\left(1-v_{i j}\right)^{1-\sigma}\left(1-\overline{v_{i j}}\right)^{\sigma}}, \quad i, j \\
& =1,2, \ldots, n .
\end{aligned}
$$

Through calculations of the above formula, the transformed consistency judgment matrix $\widetilde{R}=\left(\widetilde{r_{i j}}\right)_{n \times n}$ is obtained, where $\widetilde{r_{i j}}=\left(\widetilde{u_{i j}}, t \tilde{v_{i j}}\right)$. Then, according to formula (5), the consistency test is performed on the new consistency judgment matrix, and the above process is continued until the consistency test is passed. This is calculated as follows:

$$
\begin{aligned}
\mathrm{d}(\bar{R}, R) & =\frac{1}{2(n-1)(n-2)} \sum_{i=1}^{n} \sum_{j=1}^{n}\left(\left|\widetilde{u_{i j}}-u_{i j}\right|\right. \\
& \left.+\left|\tilde{v_{i j}}-v_{i j}\right|+\left|\widetilde{\pi_{i j}}-\pi_{i j}\right|\right) .
\end{aligned}
$$

4.3. Weight Calculation. Based on the intuitionistic fuzzy judgment matrix that passed the consistency test, the weight of each index is calculated, and the calculation formula is as follows [42]:

$$
\omega_{i}=\left(\frac{\sum_{j=1}^{n} u_{i j}}{\sum_{i=1}^{n} \sum_{j=1}^{n}\left(1-v_{i j}\right)}, 1-\frac{\sum_{j=1}^{n}\left(1-u_{i j}\right)}{\sum_{i=1}^{n} \sum_{j=1}^{n} v_{i j}}\right), \quad i=1,2, \ldots, n .
$$

4.4. Information Gathering. It can be seen from Table 1 that this evaluation system has 6 first-level indicators and 16 second-level indicators. Let the weight of the first-level indicator be $\omega_{k}(k=1,2, \ldots, 6)$, and the weight of the second-level indicator relative to the first-level indicator be $\omega_{k l}(k=1,2, \ldots, 6 ; l=1,2, \ldots, 4)$. The comprehensive weight of the secondary indicators relative to the total score of the plan is $W_{k l}$, and the number of secondary indicators under the primary indicator $A_{i}$ is between two and four. Since both $\omega_{k}$ and $\omega_{k l}$ are intuitionistic fuzzy numbers, their calculation should be performed using the algorithm of intuitionistic fuzzy numbers [43]:

$$
\begin{aligned}
& \alpha_{1} \oplus \alpha_{2}=\left(u_{\alpha 1}+u_{\alpha 2}-u_{\alpha 1} * u_{\alpha 2}, v_{\alpha 1} * v_{\alpha 2}\right), \\
& \alpha_{1} \otimes \alpha_{2}=\left(u_{\alpha 1} * u_{\alpha 2}, v_{\alpha 1}+v_{\alpha 2}-v_{\alpha 1} * v_{\alpha 2}\right) .
\end{aligned}
$$

Integration of qualitative index information uses the above formula, while the quantitative index uses the simulated value of the actual statistics.

The qualitative indicators should be deblurred so that they can form an initial decision matrix with the quantitative indicators. The deblurring algorithms of intuitionistic fuzzy sets mainly include the maximum truth value method, weighted average method, and centroid method [44]. This article uses the maximum truth method, and the formula is as follows:

$$
T_{v}(u)=\mu_{v}(u)+\frac{1+\mu_{v}(u)-\pi_{v}(u)}{2} \pi_{v}(u) .
$$

Here, $\mu_{v}(u)$ represents the degree of membership, $\pi_{v}(u)$ represents the degree of hesitation, and $T_{v}(u)$ is the true value of the intuitionistic fuzzy number.

4.5. Normalized Processing. The actual value of the quantitative index obtained from statistics and the real value of the qualitative index after deblurring constitute the initial decision-making matrix for the selection of fresh agricultural product suppliers, which are standardized to obtain a standardized decision matrix. The attributes of the indicator are divided into the benefit type and the cost type. The greater the value of the benefit-type index, the better, and the smaller the value of the cost-type index, the better. Therefore, the standardized formulas for different attribute indicators are as follows:

Benefit index:

$$
c_{i j}=\frac{c_{i j}^{M}-\min c_{i j}^{M}}{\max c_{i j}^{M}-\min c_{i j}^{M}} .
$$

Cost index:

$$
c_{i j}=\frac{\max c_{i j}^{M}-c_{i j}^{M}}{\max c_{i j}^{M}-\min c_{i j}^{M}} .
$$

4.6. TODIM Method to Calculate Dominance. This method is based on the description provided by expert experience, and it judges the merits of each evaluation object by calculating the overall superiority of the evaluation object relative to other evaluation objects. The main steps are as follows [45]:

(1) The predominance matrix $V=\left[\delta\left(a_{i}, a_{k}\right)_{n \times n}\right]$ of the evaluation objects is calculated, and $\delta\left(a_{i}, a_{k}\right)$ represents the predominance of the evaluation object $a_{i}$ relative to the evaluation object $a_{k}$. The calculation formula is given by 


$$
\delta\left(a_{i}, a_{k}\right)=\sum_{j=1}^{n} \varphi_{j}\left(a_{i}, a_{k}\right) .
$$

Here, $\varphi_{j}\left(a_{i}, a_{k}\right)$ represents the dominance of the evaluation object $a_{i}$ relative to the evaluation object $a_{k}$ with respect to the index $c_{j}$. The calculation formula of $\varphi_{j}\left(a_{i}, a_{k}\right)$ is as follows:

(a) $\varphi_{j}\left(a_{i}, a_{k}\right)=\sqrt{\frac{\left(x_{i j}-x_{k j}\right) w_{r j}}{\sum_{j=1}^{n} w_{r j}}}, \quad x_{i j}-x_{k j}>0$,

(b) $\varphi_{j}\left(a_{i}, a_{k}\right)=0, \quad x_{i j}-x_{k j}=0$,

(c) $\varphi_{j}\left(a_{i}, a_{k}\right)=-\frac{1}{\theta} \sqrt{\frac{\left(x_{k j}-x_{i j}\right) \sum_{j=1}^{n} w_{r j}}{w_{r j}}}, \quad x_{i j}-x_{k j}<0$,

where $x_{i j}, x_{k j}$ are real numbers; $w_{r j}$ is the relative weight of the index relative to the reference index $c_{j}$, $w_{r j}=\left(w_{c j} / w^{*}\right)$, where $w^{*}=\max \left\{w_{c j}, j=1,2, \ldots\right.$, $n\} ; \theta$ is the attenuation coefficient in the face of loss, and its value range is $0<\theta<\left(\left(\sum_{j=1}^{n} w_{r j}\right) /\left(w_{r j}\right)\right)$, which is generally 2.25 , indicating the ability of the decision-maker to avoid mistakes.

(2) The formula for calculating the overall advantage $T_{d}$ of the evaluation object $a_{i}$ relative to all other evaluation objects is as follows:

$$
T_{d}=\sum_{k=1}^{m} \delta\left(a_{i}, a_{k}\right) .
$$

(3) A comprehensive score of the evaluation object is calculated.

The comprehensive score $\varepsilon\left(a_{i}\right)$ of the evaluation object $a_{i}$ is obtained by normalizing the overall advantage $T_{d}$ of the evaluation object. Then, all evaluation objects are sorted according to the size of $\varepsilon\left(a_{i}\right)$. The larger the $\varepsilon\left(a_{i}\right)$, the better the evaluation object $a_{i}$. The calculation formula of $\varepsilon\left(a_{i}\right)$ is as follows:

$$
\varepsilon\left(a_{i}\right)=\frac{T_{d}-\min \left\{T_{d}\right\}}{\max \left\{T_{d}\right\}-\min \left\{T_{d}\right\}} .
$$

\section{Case Study}

5.1. Consistency Check. The intuitionistic fuzzy data in the intuitionistic fuzzy judgment matrix in this paper were obtained by experts. Based on the established index system for supplier selection criteria (Table 1), this paper established seven intuitionistic fuzzy judgment matrices as shown in Table 3.

According to equations (2) and (3), the intuitionistic fuzzy consistency test matrix $\bar{R}$ was calculated and transformed as shown in Table 4.

The next step was to calculate the consistency according to equation (1) and get $\mathrm{d}(\bar{R}, R)=0.0940<0.1$. This shows that the consistency test passed.

Table 5 shows the original matrix. According to equations (2) and (3), the intuitionistic fuzzy consistency test matrix $\bar{R}$ was calculated and transformed as shown in Table 6.

It can be seen that $\bar{R}=R$, that is, the consistency check matrix was the same as the original matrix (Table 5). In the next step, the consistency was calculated according to equation (1) as $\mathrm{d}(\bar{R}, R)=0<0.1$, which shows that the consistency test passed. All the following $2 \times 2$ matrices (Tables 7 and 8 ) have the same reasoning.

Table 9 shows the original matrix. According to equations (2) and (3), the intuitionistic fuzzy consistency test matrix $\bar{R}$ was calculated and transformed as shown in Table 10.

In the same way, according to formula (1), the consistency was calculated as $\mathrm{d}(\bar{R}, R)=0.0702<0.1$, which shows the consistency test passed.

Table 11 shows the original matrix. According to equations (2) and (3), the intuitionistic fuzzy consistency test matrix $\bar{R}$ was calculated and transformed as shown in Table 12 .

According to formula (1), the consistency was calculated as $\mathrm{d}(\bar{R}, R)=0.0976<0.1$, which shows the consistency test passed.

Table 13 shows the original matrix. According to equations (2) and (3), the intuitionistic fuzzy consistency test matrix $\bar{R}$ was calculated and transformed as shown in Table 14

According to formula (1), the consistency was calculated as $\mathrm{d}(\bar{R}, R)=0.0791<0.1$, which shows the consistency test passed.

5.2. Weight Calculation. After calculations in the previous step, all intuitionistic fuzzy judgment matrices passed the consistency test. Substituting all the matrices $\bar{R}$ that passed the test into equation (6), the weights in the first-level index are as follows:

$$
\begin{aligned}
& \omega_{1}=(0.1428,0.7735), \\
& \omega_{2}=(0.1863,0.7366), \\
& \omega_{3}=(0.1527,0.7672), \\
& \omega_{4}=(0.1241,0.7804), \\
& \omega_{5}=(0.0741,0.8516), \\
& \omega_{6}=(0.1056,0.8178),
\end{aligned}
$$


TABLE 3: Intuitionistic fuzzy judgment matrix of first-level indicators.

\begin{tabular}{lcccccc}
\hline First-level indicators & $\begin{array}{c}\text { Environmental } \\
\text { management } \\
\text { system } \mathbf{A}_{1}\end{array}$ & $\begin{array}{c}\text { Environmental } \\
\text { protection } \mathbf{A}_{2}\end{array}$ & Cost $\mathbf{A}_{3}$ & Pollution $\mathbf{A}_{4}$ & $\begin{array}{c}\text { Use of packaging } \\
\text { materials } \mathbf{A}_{5}\end{array}$ \\
\hline Food safety $\mathbf{A}_{6}$
\end{tabular}

TABLE 4: Intuitionistic fuzzy consistency test matrix of first-level indicators.

\begin{tabular}{|c|c|c|c|c|c|c|}
\hline First-level indicators & $\begin{array}{c}\text { Environmental } \\
\text { management } \\
\text { system } \mathbf{A}_{1}\end{array}$ & $\begin{array}{l}\text { Environmental } \\
\text { protection } \mathbf{A}_{2}\end{array}$ & Cost $\mathbf{A}_{3}$ & Pollution $\mathbf{A}_{4}$ & $\begin{array}{c}\text { Use of } \\
\text { packaging } \\
\text { materials } \mathbf{A}_{5}\end{array}$ & Food safety $\mathbf{A}_{6}$ \\
\hline $\begin{array}{l}\text { Environmental management } \\
\text { system } \mathbf{A}_{1}\end{array}$ & $(0.5,0.5)$ & $(0.35,0.6)$ & $(0.4468,0.5)$ & $(0.4495,0.3416)$ & $(0.5927,0.2061)$ & $(0.5403,0.2648)$ \\
\hline Environmental protection $\mathbf{A}_{2}$ & $(0.6,0.35)$ & $(0.5,0.5)$ & $(0.6,0.4)$ & $(0.6,0.2642)$ & $(0.7574,0.1198)$ & $(0.6991,0.1937)$ \\
\hline Cost $\mathbf{A}_{3}$ & $(0.5,0.4468)$ & $(0.4,0.6)$ & $(0.5,0.5)$ & $(0.5,0.35)$ & $(0.6,0.1186)$ & $(0.5785,0.2975)$ \\
\hline Pollution $\mathbf{A}_{4}$ & $(0.3416,0.4495)$ & $(0.2642,0.6)$ & $(0.35,0.5)$ & $(0.5,0.5)$ & $(0.6,0.2)$ & $(0.4468,0.2727)$ \\
\hline Use of packaging materials $\mathbf{A}_{5}$ & $(0.2061,0.5927)$ & $(0.1198,0.7574)$ & $(0.1186,0.6)$ & $(0.2,0.6)$ & $(0.5,0.5)$ & $(0.35,0.6)$ \\
\hline Food safety $\mathbf{A}_{6}$ & $(0.2648,0.5403)$ & $(0.1937,0.6991)$ & $(0.2975,0.5785)$ & $(0.2727,0.4468)$ & $(0.6,0.35)$ & $(0.5,0.5)$ \\
\hline
\end{tabular}

TABle 5: Intuitionistic fuzzy judgment matrix of secondary indicators of the environmental management system.

\begin{tabular}{lcc}
\hline A1 second-level indicator & ISO 14000 certification $\mathbf{B}_{11}$ & Environmental policy and plan $\mathbf{B}_{12}$ \\
\hline ISO 14000 certification $\mathbf{B}_{11}$ & $(0.5,0.5)$ & $(0.5,0.45)$ \\
Environmental policy and plan $\mathbf{B}_{12}$ & $(0.45,0.5)$ & $(0.5,0.5)$ \\
\hline
\end{tabular}

TABLE 6: Intuitionistic fuzzy consistency test matrix of secondary indicators of environmental management system.

\begin{tabular}{lcc}
\hline A1 second-level indicator & ISO 14000 certification $\mathbf{B}_{11}$ & Environmental policy and plan $\mathbf{B}_{12}$ \\
\hline ISO 14000 certification $\mathbf{B}_{11}$ & $(0.5,0.5)$ & $(0.5,0.45)$ \\
Environmental policy and plan $\mathbf{B}_{12}$ & $(0.45,0.5)$ & $(0.5,0.5)$ \\
\hline
\end{tabular}

TABLe 7: Intuitionistic fuzzy judgment matrix of secondary indicators of environmental protection.

\begin{tabular}{lcc}
\hline A2 second-level indicator & Environmental restoration $\mathbf{B}_{21}$ & Environmental governance $\mathbf{B}_{22}$ \\
\hline Environmental restoration $\mathbf{B}_{21}$ & $(0.5,0.5)$ & $(0.5,0.5)$ \\
Environmental governance $\mathbf{B}_{22}$ & $(0.5,0.5)$ & $(0.5,0.5)$ \\
\hline
\end{tabular}

TABle 8: Intuitionistic fuzzy judgment matrix of the second-level food safety index.

\begin{tabular}{lcc}
\hline A6 second-level indicator & Reduce food additives $\mathbf{B}_{61}$ & Green R \& D and innovation $\mathbf{B}_{62}$ \\
\hline Reduce food additives $\mathbf{B}_{61}$ & $(0.5,0.5)$ & $(0.45,0.5)$ \\
Green R \& D and innovation $\mathbf{B}_{62}$ & $(0.5,0.45)$ & $(0.5,0.5)$ \\
\hline
\end{tabular}


TABLE 9: Intuitionistic fuzzy judgment matrix of secondary cost indicators.

\begin{tabular}{lccc}
\hline A3 second-level indicator & Energy consumption $\mathbf{B}_{31}$ & Logistics costs $\mathbf{B}_{32}$ & Product net price $\mathbf{B}_{33}$ \\
\hline Energy consumption $\mathbf{B}_{31}$ & $(0.5,0.5)$ & $(0.65,0.15)$ & $(0.45,0.35)$ \\
Logistics costs $\mathbf{B}_{32}$ & $(0.15,0.65)$ & $(0.5,0.5)$ & $(0.3,0.7)$ \\
Product net price $\mathbf{B}_{33}$ & $(0.35,0.45)$ & $(0.7,0.3)$ & $(0.5,0.5)$ \\
\hline
\end{tabular}

TABLE 10: Intuitionistic fuzzy consistency test matrix of the second-level cost index.

\begin{tabular}{lccc}
\hline A3 second-level indicator & Energy consumption $\mathbf{B}_{31}$ & Logistics costs $\mathbf{B}_{32}$ & Product net price $\mathbf{B}_{33}$ \\
\hline Energy consumption $\mathbf{B}_{31}$ & $(0.5,0.5)$ & $(0.65,0.15)$ & $(0.4432,0.2916)$ \\
Logistics costs $\mathbf{B}_{32}$ & $(0.15,0.65)$ & $(0.5,0.5)$ & $(0.3,0.7)$ \\
Product net price $\mathbf{B}_{33}$ & $(0.2916,0.4432)$ & $(0.7,0.3)$ & $(0.5,0.5)$ \\
\hline
\end{tabular}

The weights of the secondary indicators are as follows:

TABLE 11: Intuitionistic fuzzy judgment matrix for secondary indicators of pollution.

\begin{tabular}{lccr}
\hline A4 second-level indicator & Air pollutant production $\mathbf{B}_{41}$ & Wastewater production $\mathbf{B}_{42}$ & Solid waste generation $\mathbf{B}_{43}$ \\
\hline Air pollutant production $\mathbf{B}_{41}$ & $(0.5,0.5)$ & $(0.45,0.6)$ & $(0.6,0.35)$ \\
Wastewater production $\mathbf{B}_{42}$ & $(0.6,0.45)$ & $(0.5,0.5)$ & $(0.5,0.45)$ \\
Solid waste generation $\mathbf{B}_{43}$ & $(0.35,0.6)$ & $(0.45,0.5)$ & $(0.5,0.5)$ \\
\hline
\end{tabular}

TABLE 12: Intuitionistic fuzzy consistency test matrix for secondary indicators of pollution.

\begin{tabular}{lccr}
\hline A4 second-level indicator & Air pollutant production $\mathbf{B}_{41}$ & Wastewater production $\mathbf{B}_{42}$ & Solid waste generation $\mathbf{B}_{43}$ \\
\hline Air pollutant production $\mathbf{B}_{41}$ & $(0.5,0.5)$ & $(0.45,0.6)$ & $(0.45,0.3058)$ \\
Wastewater production $\mathbf{B}_{42}$ & $(0.6,0.45)$ & $(0.5,0.5)$ & $(0.5,0.45)$ \\
Solid waste generation $\mathbf{B}_{43}$ & $(0.3058,0.45)$ & $(0.45,0.5)$ & $(0.5,0.5)$ \\
\hline
\end{tabular}

TABLE 13: Intuitionistic fuzzy judgment matrix for the use of secondary indicators for packaging materials.

\begin{tabular}{lcccc}
\hline A5 second-level indicator & Reusability $\mathbf{B}_{51}$ & $\begin{array}{c}\text { Biodegradable products } \\
\mathbf{B}_{52}\end{array}$ & $\begin{array}{c}\text { Use recycled materials } \\
\mathbf{B}_{53}\end{array}$ & $\begin{array}{c}\text { Use of hazardous substances } \\
\mathbf{B}_{54}\end{array}$ \\
\hline Reusability $\mathbf{B}_{51}$ & $(0.5,0.5)$ & $(0.55,0.4)$ & $(0.45,0.55)$ & $(0.4,0.5)$ \\
Biodegradable products $\mathbf{B}_{52}$ & $(0.4,0.55)$ & $(0.5,0.5)$ & $(0.5,0.45)$ & $(0.5,0.3)$ \\
Use recycled materials $\mathbf{B}_{53}$ & $(0.55,0.45)$ & $(0.45,0.5)$ & $(0.5,0.5)$ & $(0.55,0.45)$ \\
Use of hazardous substances & $(0.5,0.4)$ & $(0.3,0.5)$ & $(0.45,0.55)$ & $(0.5,0.5)$ \\
$\mathbf{B}_{54}$ & & & & \\
\hline
\end{tabular}

TABLE 14: Intuitionistic fuzzy consistency test matrix for the use of secondary indicators for packaging materials.

\begin{tabular}{lcccc}
\hline A5 second-level indicator & Reusability $\mathbf{B}_{51}$ & $\begin{array}{c}\text { Biodegradable products } \\
\mathbf{B}_{52}\end{array}$ & $\begin{array}{c}\text { Use recycled materials } \\
\mathbf{B}_{53}\end{array}$ & $\begin{array}{c}\text { Use of hazardous substances } \\
\mathbf{B}_{54}\end{array}$ \\
\hline Reusability $\mathbf{B}_{51}$ & $(0.5,0.5)$ & $(0.55,0.4)$ & $(0.55,0.3529)$ & $(0.525,0.3483)$ \\
Biodegradable products $\mathbf{B}_{52}$ & $(0.4,0.55)$ & $(0.5,0.5)$ & $(0.5,0.45)$ & $(0.55,0.401)$ \\
Use recycled materials $\mathbf{B}_{53}$ & $(0.3529,0.55)$ & $(0.45,0.5)$ & $(0.5,0.5)$ & $(0.55,0.45)$ \\
Use of hazardous substances & $(0.3483,0.525)$ & $(0.401,0.55)$ & $(0.45,0.55)$ & $(0.5,0.5)$ \\
$\mathbf{B}_{54}$ & & & & $(0.5)$ \\
\hline
\end{tabular}




$$
\begin{aligned}
& \omega_{11}=(0.4878,0.4615), \\
& \omega_{12}=(0.4634,0.4872), \\
& \omega_{21}=(0.5,0.5), \\
& \omega_{22}=(0.5,0.5), \\
& \omega_{31}=(0.3209,0.4898), \\
& \omega_{32}=(0.1913,0.7150), \\
& \omega_{33}=(0.3004,0.5646), \\
& \omega_{41}=(0.2951,0.6254), \\
& \omega_{42}=(0.3373,0.6240), \\
& \omega_{43}=(0.2647,0.6358), \\
& \omega_{51}=(0.2538,0.6855), \\
& \omega_{52}=(0.2329,0.7248), \\
& \omega_{53}=(0.2213,0.7378), \\
& \omega_{54}=(0.2030,0.7542), \\
& \omega_{61}=(0.4634,0.4872), \\
& \omega_{62}=(0.4878,0.4615),
\end{aligned}
$$

\subsection{Information Aggregation}

5.3.1. Calculating the Total Weight. After calculating the weights of the first-level indicators and the second-level indicators, they are used in equation (8) for information integration to obtain the total weight. The results are shown in Table 15.

5.3.2. Deblurring. The total weight of the information aggregation in the previous step is a fuzzy number, which is then used in equation (9) to calculate the true value of the total weight as follows: $[0.0963,0.0916,0.1135,0.1135$, 0.0832, 0.0476, 0.0734, 0.0592, 0.0623, 0.0561, 0.0326, 0.0290, $0.0276,0.0257,0.0712,0.0749]$. Then, it is normalized to get $[0.0911,0.0866,0.1073,0.1073,0.0786,0.0450,0.0694$, 0.0560, 0.0589, 0.0530, 0.0308, 0.0274, 0.0261, 0.0243, 0.0674, $0.0708]$.

5.3.3. Weight Ratio Analysis. It can be seen from Figure 3 that the highest proportions of index weights were $B_{11}, B_{12}$, $B_{21}, B_{22}, B_{31}$, and $B_{62}$, followed by $B_{33}$ and $B_{61}$. The sum of the two accounted for $67.6 \%$, which can be regarded as the most influential indicator. From the perspective of the meaning of the indicators, environmental policies and certification, environmental restoration, and governance reflect the suppliers' ability to harmlessly deal with pollution and their efforts to protect the ecological environment. The second is the cost of energy consumed by agricultural products and the ability to develop new clean technologies, which shows the economic profitability of the organization and the level of waste disposal. From the perspective of sustainability combined with the weight of indicators, the two were in line with objective cognition and scientific laws. The results show that suppliers should first consider possible ecological damage and pollution control, and then they should pay attention to controlling product cost and technological innovation for disposal.

5.4. Decision Matrix Normalization. Experts scored the qualitative indicators of the four suppliers, and then the maximum value method was used to decompose the fuzzy numbers to obtain the true values of the qualitative indicators of each supplier. The quantitative values obtained approximately accurate values through statistical data and simulation. Finally, the initial decision matrix composed of qualitative indicators and quantitative indicators is shown in Table 16.

Among them, the yellow part indicates that the indicator is a cost-based indicator, and the rest are benefit-based indicators. Then, the above indicators were divided into cost-type indicators and benefit-type indicators, and they were substituted into formulas (10) and (11), respectively. The standardized decision matrix is shown in Table 17.

5.5. Computing Dominance. After obtaining the normalized decision matrix and the weight of each indicator, the predominance $\delta\left(a_{i}, a_{k}\right)$ of supplier $a_{i}$ relative to supplier $a_{k}$ with respect to indicator $c_{j}$ was calculated according to equation (13), where $\theta$ takes 2.25 [34]. Then, according to equation (12), the matrix of comparative advantages between suppliers was obtained as shown in Table 18.

The advantage comparison matrix was standardized according to equations (14) and (15) to obtain the comprehensive score $\varepsilon\left(a_{i}\right)$ of each supplier: $\varepsilon\left(a_{1}\right)=0.7476$, $\varepsilon\left(a_{2}\right)=0.6643, \varepsilon\left(a_{3}\right)=0$, and $\varepsilon\left(a_{4}\right)=1$. Sorting by size shows that $a_{4}$ was the best supplier, and the enterprise should choose supplier $a_{4}$ to supply fresh agricultural products.

As shown in Figure 4, the overall advantage of each supplier and the trend of the final comprehensive score were the same. Compared with other suppliers, supplier $\mathrm{C} 4$ had a maximum advantage of 3.9266 and the highest overall score of 1 , followed by suppliers $\mathrm{C} 1, \mathrm{C} 2$, and $\mathrm{C} 3$. The figure shows that the overall advantage of supplier C3 was far lower than that of other manufacturers. From the above calculations, it can be seen that the largest of the cost-based indicators came from C3. This means that, in terms of environmental pollution and product costs, supplier C3 had the highest proportion compared with other manufacturers, so it had the lowest sustainability and the lowest ranking. Supplier C4 was mostly in the bottom position regarding cost-based indicators, and mostly in the first place in 
TABLE 15: Total weight table.

\begin{tabular}{lcr}
\hline First-level indicators & Secondary indicators & Total weight \\
\hline$(0.1428,0.7735)$ & $(0.4878,0.4615)$ & $(0.0697,0.8780)$ \\
& $(0.4634,0.4872)$ & $(0.0662,0.8839)$ \\
\hline$(0.1863,0.7366)$ & $(0.5,0.5)$ & $(0.0932,0.8683)$ \\
& $(0.5,0.5)$ & $(0.0932,0.8683)$ \\
\hline & $(0.3209,0.4898)$ & $(0.0490,0.8812)$ \\
& $(0.1913,0.7150)$ & $(0.0292,0.9337)$ \\
$(0.1527,0.7672)$ & $(0.3004,0.5646)$ & $(0.0459,0.8986)$ \\
\hline & $(0.2951,0.6254)$ & $(0.0366,0.9177)$ \\
& $(0.3373,0.6240)$ & $(0.0419,0.9174)$ \\
$(0.0741,0.8516)$ & $(0.2647,0.6358)$ & $(0.0328,0.9200)$ \\
\hline & $(0.2538,0.6855)$ & $(0.0188,0.9533)$ \\
& $(0.2329,0.7248)$ & $(0.0173,0.9592)$ \\
& $(0.2213,0.7378)$ & $(0.0164,0.9611)$ \\
& $(0.2030,0.7542)$ & $(0.0150,0.9635)$ \\
\hline
\end{tabular}

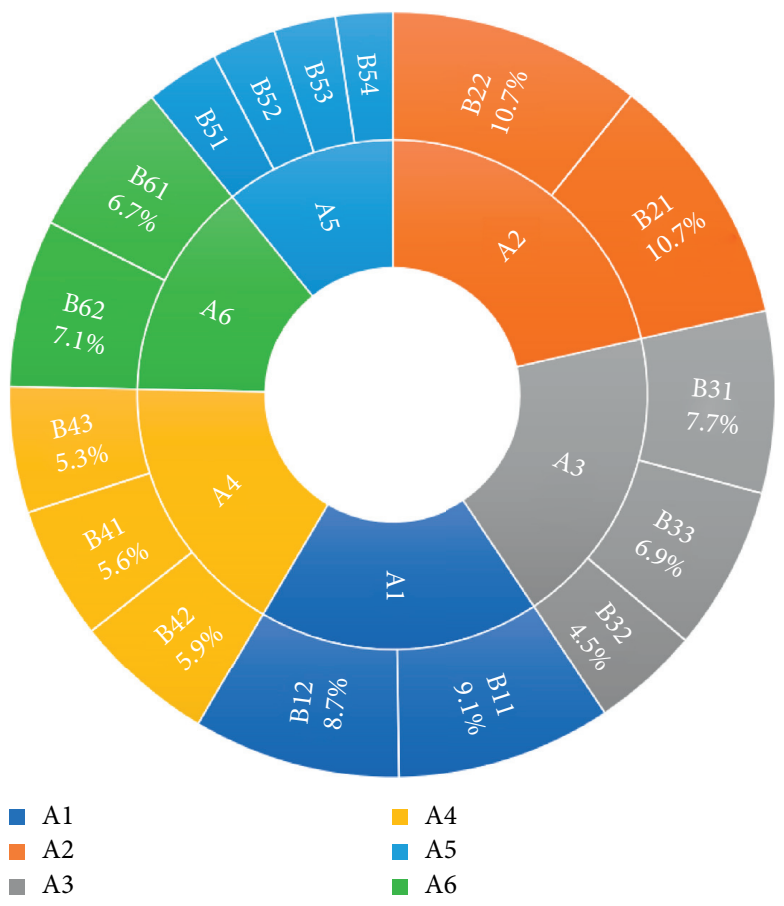

Figure 3: Proportion of total weight.

efficiency-based indicators. This shows that supplier C4 achieved a better balance between economic development, social responsibility, and environmental protection than other manufacturers, which ultimately makes it the most sustainable and gives it the highest comprehensive score.
5.6. Sensitivity Analysis. The purpose of the sensitivity analysis is to verify whether there are differences in the results of the selection of sustainable suppliers of fresh agricultural products under different $\theta$ values (representing the different ability of decision-makers to avoid risks). In this 
TABLE 16: Initial decision matrix.

\begin{tabular}{|c|c|c|c|c|c|c|}
\hline Index/supplier & $\mathrm{C} 1$ & $\mathrm{C} 2$ & $\mathrm{C} 3$ & $\mathrm{C} 4$ & $\max c j$ & $\min c j$ \\
\hline b1 ISO 14000 certification & 0.7716 & 0.78 & 0.6675 & 0.7513 & 0.78 & 0.6675 \\
\hline b2 environmental policy and plan & 0.4338 & 0.6456 & 0.36 & 0.675 & 0.675 & 0.36 \\
\hline b3 environmental restoration & 0.6464 & 0.7195 & 0.3648 & 0.8613 & 0.8613 & 0.3648 \\
\hline b4 environmental governance & 0.6563 & 0.6 & 0.408 & 0.6225 & 0.6563 & 0.408 \\
\hline b5 energy consumption & 518 & 532 & 568 & 504 & 568 & 504 \\
\hline b6 logistics costs & 1320 & 1632 & 1893 & 1100 & 1893 & 1100 \\
\hline b7 product net price & 2530 & 2715 & 2900 & 2300 & 2900 & 2300 \\
\hline b8 air pollutant production & 54 & 55 & 58 & 52 & 58 & 52 \\
\hline b9 wastewater production & 1300 & 1520 & 1890 & 1100 & 1890 & 1100 \\
\hline b10 solid waste generation & 4330 & 4650 & 4882 & 4210 & 4882 & 4210 \\
\hline b11 reusability & 50 & 55 & 32 & 60 & 60 & 32 \\
\hline b12 biodegradable products & 62 & 50 & 43 & 75 & 75 & 43 \\
\hline b13 use recycled materials & 30 & 32 & 28 & 38 & 38 & 28 \\
\hline b14 use of hazardous substances & 120 & 130 & 150 & 105 & 150 & 105 \\
\hline b15 reduce food additives & 0.3863 & 0.4077 & 0.2409 & 0.4125 & 0.4125 & 0.2409 \\
\hline b16 green $\mathrm{R} \& \mathrm{D}$ and innovation & 0.2288 & 0.2334 & 0.1713 & 0.2176 & 0.2334 & 0.1713 \\
\hline
\end{tabular}

TABLE 17: Normalized decision matrix.

\begin{tabular}{|c|c|c|c|c|}
\hline Index/supplier & $\mathrm{C} 1$ & $\mathrm{C} 2$ & $\mathrm{C} 3$ & $\mathrm{C} 4$ \\
\hline b1 ISO 14000 certification & 0.9259 & 1 & 0 & 0.7456 \\
\hline b2 environmental policy and plan & 0.2343 & 0.9067 & 0 & 1 \\
\hline b3 environmental restoration & 0.5672 & 0.7144 & 0 & 1 \\
\hline b4 environmental governance & 1 & 0.7733 & 0 & 0.8639 \\
\hline b5 energy consumption & 0.7813 & 0.5625 & 0 & 1 \\
\hline b6 logistics costs & 0.7226 & 0.3291 & 0 & 1 \\
\hline b7 product net price & 0.6167 & 0.3083 & 0 & 1 \\
\hline b8 air pollutant production & 0.6667 & 0.5 & 0 & 1 \\
\hline b9 wastewater production & 0.7468 & 0.4684 & 0 & 1 \\
\hline b10 solid waste generation & 0.8214 & 0.3452 & 0 & 1 \\
\hline b11 reusability & 0.6429 & 0.8214 & 0 & 1 \\
\hline b12 biodegradable products & 0.5938 & 0.2188 & 0 & 1 \\
\hline b13 use recycled materials & 0.2 & 0.4 & 0 & 1 \\
\hline b14 use of hazardous substances & 0.6667 & 0.4444 & 0 & 1 \\
\hline b15 reduce food additives & 0.8473 & 0.9720 & 0 & 1 \\
\hline b16 green $\mathrm{R} \& \mathrm{D}$ and innovation & 0.9259 & 1 & 0 & 0.7456 \\
\hline
\end{tabular}

TABle 18: Dominant comparison matrix.

\begin{tabular}{cccccrr}
\hline & $\mathrm{C} 1$ & $\mathrm{C} 2$ & $\mathrm{C} 3$ & $\mathrm{C} 4$ & $\mathrm{~T}_{\mathbf{d}}$ & $\varepsilon\left(\mathbf{a}_{\mathbf{i}}\right)$ \\
\hline C1 & 0 & -4.3945 & 3.2165 & -15.5640 & -16.7420 & 0.7476 \\
$\mathrm{C} 2$ & -8.9332 & 0 & 3.0584 & -17.6883 & -23.5631 & 0.6643 \\
C3 & -24.7402 & -22.8435 & 0 & -30.3814 & -77.9651 & 0 \\
C4 & -0.0538 & 0.3925 & 3.5879 & 0 & 3.9266 & 1 \\
\hline
\end{tabular}

paper, two values of $\theta=3,4$ [34] were used for sensitivity analysis. Table 19 shows the comprehensive scores of various suppliers under different attenuation coefficients. According to Table 19, as the attenuation coefficient increased, the scores of suppliers C1 and C2 declined. This is because the ability of decision-makers to avoid risks became weaker and weaker, resulting in more errors in the judgment of suppliers. Figure 5 reflects the comprehensive score trend of various suppliers under different attenuation coefficient $\theta$ values. It can be seen that under the four different $\theta$ values, no matter how the decision-makers' circumvention ability changed, the final supplier selection results tended to be consistent. 


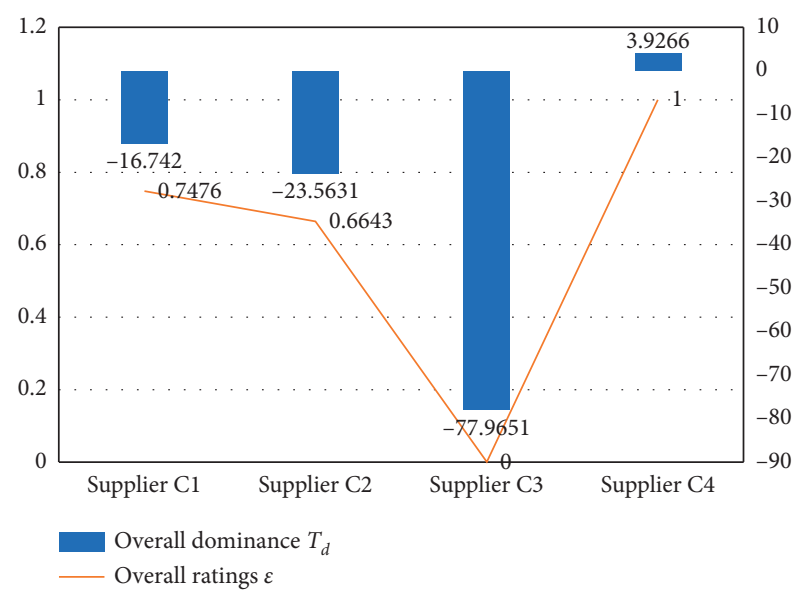

Figure 4: Dominance and comprehensive score table.

TABle 19: Comprehensive supplier scores under different attenuation coefficients.

\begin{tabular}{lcccc}
\hline Attenuation coefficient/supplier & $\mathrm{C} 1$ & $\mathrm{C} 2$ & $\mathrm{C} 3$ & $\mathrm{C} 4$ \\
\hline 2.25 & 0.7476 & 0.6643 & 0 & 1 \\
3 & 0.7445 & 0.6612 & 0 & 1 \\
4 & 0.7406 & 0.6574 & 0 & 1 \\
\hline
\end{tabular}

\section{Conclusion}

At present, there are very few studies that evaluate the sustainability of fresh agricultural product suppliers, and most indicators are selected based on economic indicators or financial indicators. However, noneconomic indicators such as social responsibility and environmental protection should be considered under the requirements of sustainable development. Therefore, this paper comprehensively considered the impact of economic development, social responsibility, and environmental protection (that is, the triple bottom line) on the sustainability of the supply of fresh agricultural products, and it built a more reasonable index system based on reference to the selection criteria of conventional suppliers. The evaluation system can help future decision-makers in selecting sustainable fresh agricultural product suppliers. This paper also combined intuitionistic fuzzy AHP and TODIM multiattribute decision-making methods to select sustainable suppliers.

When determining the index weight, the traditional supplier selection methods such as AHP, ANP, and DEMATEL cannot accurately deal with the uncertainty of expert evaluation information, and the decision information lacks scientific quantitative means. The fuzzy AHP method can better deal with the fuzziness of natural language and transform fuzzy information into accurate numbers. This fully considers the uncertainty in expert evaluation and better guarantees that the original information is not distorted.

When ranking suppliers, the supplier ranking methods such as DEA, PROMETHEE, and TOPSIS do not consider the decision-maker's subjective preference behavior, which often loses a lot of qualitative information. TODIM

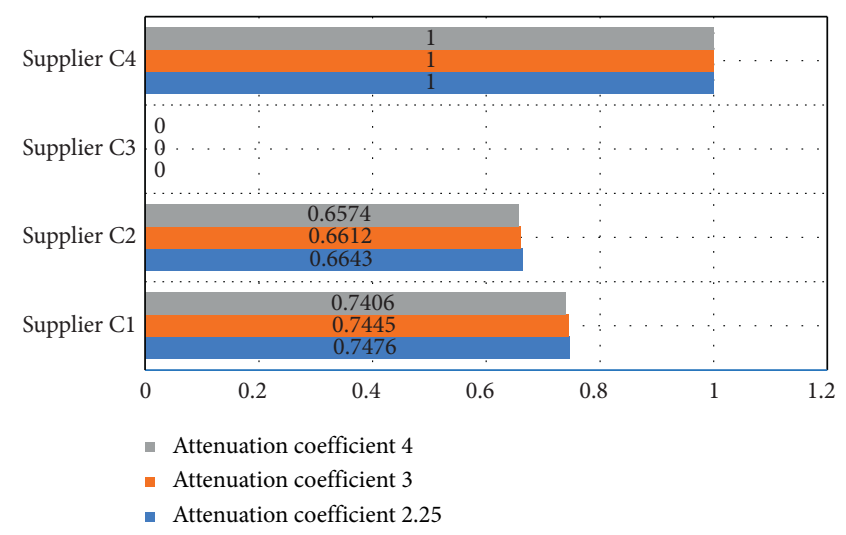

FIgURE 5: Comprehensive scores under different attenuation coefficients.

multiattribute decision-making method takes into account the psychological behavior of decision-makers, which can deal with environmental uncertainty and ensure the original information is not distorted.

In the field of sustainable supplier selection of fresh agricultural products, from the perspective of sustainability, most of the previous literature did not consider the combination of fuzzy weight determination method and traditional supplier ranking method to select fresh agricultural products suppliers. Therefore, based on the concept of sustainability, this paper uses FAHP and TODIM to select the best supplier. In order to verify the feasibility of the proposed integration method, an example sensitivity analysis was carried out in this paper. According to the final calculation results, it was found that intuitionistic fuzzy AHP and TODIM were feasible and effective for supplier selection.

In summary, this article is based on the "triple bottom line" theory to assess and enrich the sustainability model of fresh agricultural products suppliers. This research fills the gap of applying the "triple bottom line" theory and the IFAHP-TODIM method to the selection of sustainable suppliers of fresh agricultural products. Finally, the limitations and future research directions of this article are as follows:

(1) The model adopted in this paper still cannot avoid subjectivity in determining the weight of each indicator, so further research is needed.

(2) Due to the lack of research in this field, the evaluation index system in this article may not be universally applied. In the future, it is necessary to adjust the selection of indicators according to the actual economic and policy situation of various regions, so as to make the decision more effective.

(3) The future research can also start from the weight section. Further, the combination of subjective and objective weights makes the decision more reliable.

(4) The supplier selection of fresh agricultural products can make decisions more accurately with the help of big data and other data mining algorithms. 


\section{Data Availability}

The data used to support the findings of this study were supplied by experts. Data are available from the corresponding author(2019225025109@stu.scu.edu.cn) for researchers who meet the criteria for access to confidential data.

\section{Conflicts of Interest}

The authors declare that they have no conflicts of interest.

\section{References}

[1] M. M. Aung and Y. S. Chang, "Temperature management for the quality assurance of a perishable food supply chain," Food Control, vol. 40, pp. 198-207, 2014.

[2] X. Ma, S. Wang, S. M. N. Islam, and X. Liu, "Coordinating a three-echelon fresh agricultural products supply chain considering freshness-keeping effort with asymmetric information," Applied Mathematical Modelling, vol. 67, pp. 337-356, 2019.

[3] C. Aysoy, D. H. Kirli, and S. Tumen, "How does a shorter supply chain affect pricing of fresh food? evidence from a natural experiment," Food Policy, vol. 57, pp. 104-113, 2015.

[4] S. Henson, O. Masakure, and D. Boselie, "Private food safety and quality standards for fresh produce exporters: the case of Hortico Agrisystems, Zimbabwe," Food Policy, vol. 30, no. 4, pp. 371-384, 2005.

[5] A. Amindoust, S. Ahmed, A. Saghafinia, and A. Bahreininejad, "Sustainable supplier selection: a ranking model based on fuzzy inference system," Applied Soft Computing, vol. 12, no. 6, pp. 1668-1677, 2012.

[6] B. G. Smith, "Developing sustainable food supply chains," Philosophical Transactions of the Royal Society B: Biological Sciences, vol. 363, no. 1492, pp. 849-861, 2007.

[7] H. Allaoui, Y. Guo, A. Choudhary, and J. Bloemhof, "Sustainable agro-food supply chain design using two-stage hybrid multi-objective decision-making approach," Computers \& Operations Research, vol. 89, pp. 369-384, 2018.

[8] P. M. Wognum, H. Bremmers, J. H. Trienekens, J. G. A. J. van der Vorst, and J. M. Bloemhof, "Systems for sustainability and transparency of food supply chains-current status and challenges," Advanced Engineering Informatics, vol. 25, no. 1, pp. 65-76, 2011.

[9] P. W. Gerbens-Leenes, H. C. Moll, and A. J. M. Schoot Uiterkamp, "Design and development of a measuring method for environmental sustainability in food production systems," Ecological Economics, vol. 46, no. 2, pp. 231-248, 2003.

[10] C. Solér, K. Bergström, and H. Shanahan, "Green supply chains and the missing link between environmental information and practice," Business Strategy and the Environment, vol. 19, no. 1, pp. 14-15, 2009.

[11] M. Cellura, F. Ardente, and S. Longo, "From the LCA of food products to the environmental assessment of protected crops districts: a case-study in the south of Italy," Journal of Environmental Management, vol. 93, no. 1, pp. 194-208, 2012.

[12] M. J. Maloni and M. E. Brown, "Corporate social responsibility in the supply chain: an application in the food industry," Journal of Business Ethics, vol. 68, no. 1, pp. 35-52, 2006.

[13] L. Spence and M. Bourlakis, "The evolution from corporate social responsibility to supply chain responsibility: the case of Waitrose," Supply Chain Management: An International Journal, vol. 14, no. 4, pp. 291-302, 2009.
[14] O. Chkanikova and O. Mont, "Corporate supply chain responsibility: drivers and barriers for sustainable food retailing," Corporate Social Responsibility and Environmental Management, vol. 22, no. 2, pp. 65-82, 2012.

[15] C. C. Krejci, R. T. Stone, M. C. Dorneich, and S. B. Gilbert, "Analysis of food hub commerce and participation using agent-based modeling: integrating financial and social drivers," Human Factors, vol. 58, no. 1, pp. 58-79, 2016.

[16] Y. Chen, S. Wang, J. Yao, Y. Li, and S. Yang, "Socially responsible supplier selection and sustainable supply chain development: a combined approach of total interpretive structural modeling and fuzzy analytic network process," Business Strategy and the Environment, vol. 27, no. 8, pp. 1708-1719, 2018.

[17] S. Stranieri, L. Orsi, A. Banterle, and E. C. Ricci, "Sustainable development and supply chain coordination: the impact of corporate social responsibility rules in the European Union food industry," Corporate Social Responsibility and Environmental Management, vol. 26, no. 2, pp. 481-491, 2019.

[18] N. Yakovleva, J. Sarkis, and T. Sloan, "Sustainable benchmarking of supply chains: the case of the food industry," International Journal of Production Research, vol. 50, no. 5, pp. 1297-1317, 2012.

[19] R. Accorsi, S. Cholette, R. Manzini, C. Pini, and S. Penazzi, "The land-network problem: ecosystem carbon balance in planning sustainable agro-food supply chains," Journal of Cleaner Production, vol. 112, pp. 158-171, 2015.

[20] H. Allaoui, Y. Guo, and J. Sarkis, "Decision support for collaboration planning in sustainable supply chains," Journal of Cleaner Production, vol. 229, pp. 761-774, 2019.

[21] M. M. Siddh, G. Soni, R. Jain, M. K. Sharma, and V. Yadav, "Agri-fresh food supply chain quality (AFSCQ): a literature review," Industrial Management \& Data Systems, vol. 117, no. 9, pp. 2015-2044, 2017.

[22] G. Büyüközkan and G. Çifçi, "A novel fuzzy multi-criteria decision framework for sustainable supplier selection with incomplete information," Computers in Industry, vol. 62, no. 2, pp. 164-174, 2011.

[23] D. Wu and J. M. Mendel, "Computing with words for hierarchical decision making applied to evaluating a weapon system," IEEE Transactions on Fuzzy Systems, vol. 18, no. 3, pp. 441-460, 2010.

[24] Z. Chen, X. Ming, X. Zhang, D. Yin, and Z. Sun, "A roughfuzzy DEMATEL-ANP method for evaluating sustainable value requirement of product service system," Journal of Cleaner Production, vol. 228, pp. 485-508, 2019.

[25] J. Li, H. Fang, and W. Song, "Sustainable supplier selection based on SSCM practices: a rough cloud TOPSIS approach," Journal of Cleaner Production, vol. 222, pp. 606-621, 2019.

[26] S. Hosseini and A. A. Khaled, "A hybrid ensemble and AHP approach for resilient supplier selection," Journal of Intelligent Manufacturing, vol. 30, no. 1, pp. 207-228, 2016.

[27] M. Giannakis, R. Dubey, I. Vlachos, and Y. Ju, "Supplier sustainability performance evaluation using the analytic network process," Journal of Cleaner Production, vol. 247, Article ID 119439, 2020.

[28] W. Song, Z. Xu, and H.-C. Liu, "Developing sustainable supplier selection criteria for solar air-conditioner manufacturer: an integrated approach," Renewable and Sustainable Energy Reviews, vol. 79, pp. 1461-1471, 2017.

[29] A. Torres-Ruiz and A. R. Ravindran, "Use of interval data envelopment analysis, goal programming and dynamic ecoefficiency assessment for sustainable supplier management," 
Computers \& Industrial Engineering, vol. 131, pp. 211-226, 2019.

[30] M. Segura, C. Maroto, and B. Segura, "Quantifying the sustainability of products and suppliers in food distribution companies," Sustainability, vol. 11, no. 21, pp. 58-75, 2019.

[31] C. Yu, Y. Shao, K. Wang, and L. Zhang, "A group decision making sustainable supplier selection approach using extended TOPSIS under interval-valued Pythagorean fuzzy environment," Expert Systems with Applications, vol. 121, pp. 1-17, 2019.

[32] Y. Liang, J. Liu, J. Qin, and Y. Tu, "An improved multigranularity interval 2-tuple TODIM approach and its application to green supplier selection," International Journal of Fuzzy Systems, vol. 21, no. 1, pp. 129-144, 2018.

[33] S. Nie, H. Liao, X. Wu, and Z. Xu, "Green supplier selection with a continuous interval-valued linguistic TODIM method," IEEE Access, vol. 7, pp. 124315-124328, 2019.

[34] L. Wang, Y.-M. Wang, and L. Martínez, "Fuzzy TODIM method based on alpha-level sets," Expert Systems With Applications, vol. 140, Article ID 112899, 2020.

[35] G. Büyüközkan and F. Göçer, "Application of a new combined intuitionistic fuzzy MCDM approach based on axiomatic design methodology for the supplier selection problem," Applied Soft Computing, vol. 52, pp. 1222-1238, 2017.

[36] A. Cheraghalipour and S. Farsad, "A bi-objective sustainable supplier selection and order allocation considering quantity discounts under disruption risks: a case study in plastic industry," Computers \& Industrial Engineering, vol. 118, pp. 237-250, 2018.

[37] M. Abdel-Basset, M. Mohamed, and F. Smarandache, "A hybrid neutrosophic group ANP-TOPSIS framework for supplier selection problems," Symmetry, vol. 10, no. 6, p. 21, 2018.

[38] F. Ecer and D. Pamucar, "Sustainable supplier selection: a novel integrated fuzzy best worst method (F-BWM) and fuzzy CoCoSo with Bonferroni (CoCoSo'B) multi-criteria model," Journal of Cleaner Production, vol. 266, Article ID 121981, 2020.

[39] G. Bektur, "An integrated methodology for the selection of sustainable suppliers and order allocation problem with quantity discounts, lost sales and varying supplier availabilities," Sustainable Production and Consumption, vol. 23, pp. 111-127, 2020.

[40] A. H. Azadnia, M. Z. M. Saman, and K. Y. Wong, "Sustainable supplier selection and order lot-sizing: an integrated multiobjective decision-making process," International Journal of Production Research, vol. 53, no. 2, pp. 383-408, 2014.

[41] E. Szmidt and J. Kacprzyk, "Amount of information and its reliability in the ranking of Atanassov's intuitionistic fuzzy alternatives," Studies in Computational Intelligence, Springer, Berlin, Germany, pp. 7-19, 2009.

[42] Z. Xu and H. Liao, "Intuitionistic fuzzy analytic hierarchy process," IEEE Transactions on Fuzzy Systems, vol. 22, no. 4, pp. 749-761, 2014.

[43] X. Zeshui, "Intuitionistic fuzzy aggregation operators," IEEE Transactions on Fuzzy Systems, vol. 15, no. 6, pp. 1179-1187, 2007.

[44] A. Chandramohan, M. V. C. Rao, and M. S. Arumugam, "Two new and useful defuzzification methods based on root mean square value," Soft Computing, vol. 10, no. 11, pp. 1047-1059, 2006.

[45] Z.-P. Fan, X. Zhang, F.-D. Chen, and Y. Liu, "Extended TODIM method for hybrid multiple attribute decision making problems," Knowledge-Based Systems, vol. 42, pp. 40-48, 2013. 